\title{
Exploring the use of a humanoid robot to engage children with Autism Spectrum Disorder (ASD)
}

\section{Quick Overview:}

We present a study aimed at exploring whether a humanoid robot may improve the effectiveness of educational interventions targeting children with autism spectrum disorders (ASD). Preliminary results with three preschool children with ASD indicate that interacting with a humanoid robot facilitate engagement and goal achievement in educational activities.

\section{Introduction}

According to the Diagnostic and Statistical Manual of Mental Disorders [1] children with autism spectrum disorder (hereafter, children with ASD) have persistent deficits in social communication and interaction across multiple contexts; restricted, repetitive patterns of behaviour, e.g. stereotyped or repetitive motor movements or adherence to routines. They find it difficult to recognize body language, to make eye contact, to talk about personal feelings, and to understand other people's emotions [2].

Recent literature has highlighted that children with ASD appear to have a special interest in computerized activities [3], and have identified the advantages that computers provide with respect to the core deficits of ASD. These include the consistency of a clearly defined task and the usually specific focus of attention due to reduced distractions from unnecessary sensory stimuli [3]. On the basis of these assumptions, in recent years, robots have been incorporated into treatment interventions targeting children with ASD [4]. Specifically, the use of robots, contrary to people's social behaviour, which can be very subtle and unpredictable, may allow for a simplified predictable and reliable environment where the complexity of interaction can be controlled and gradually increased [5].

Although still a nascent literature, positive outcomes have demonstrated that robotbased treatment may represent a valid additional component in ASD therapy [4, 6, 7]. Robots are in particular considered a valid support to promote attention and engagement of children with ASD in therapy-like scenarios [4, 8]. Literature reports positive effects of robot presence on engagement of children with ASD on proposed therapeutic activities [4], regardless robot appearances and capabilities, thus supporting the idea that robots may serve as a facilitator of the therapeutic intervention. Engagement is a critical feature of effective learning interventions [9], and is considered "the single best predictor" of learning for children with intellectual disabilities [10; p. 2]. Children with ASD spend less time engaged in social and nonsocial activities than their typically developing peers and children with other developmental disabilities resulting in reduced learning opportunities [11].

Despite showing great promise, however, concerns remain about the potential of robots in clinical as well as in educational practices [6]. As noted by Oldenziel and colleagues [12], the interest in adopting new technologies quickly decreases when existing practices require too many changes, and this may be especially true for the introduction of robotic applications in several fields, including education and healthcare [13]. 
Here we assume that, for an effective transferability of robotic applications in healthcare sector to happen, it is required that researchers move from documenting the potential of robots in laboratory conditions to developing more accessible, quantifiable and individualized robot-based treatment tools to address core vulnerabilities related to ASD in specific real clinical settings. In this view, the present study reports on the preliminary results of the application of a robot-based intervention aimed at exploring whether a humanoid robot may help healthcare operators to engage children with ASD in educational activities. The focus of the present contribution is on effectiveness of robot-based activities in routine clinical practice. Information about feasibility and usability of the robot in daily practice will be reported elsewhere. The study was conducted in collaboration with an Italian public-funded ASD service, and the results will help developing a protocol to introducing robot-based treatment as an additional component of the service routine clinical practice.

\section{Methods}

The study was conducted within an European project (further details will be given in case of acceptance of the paper to assure anonymity). The Project was aimed at demonstrating that cognitive development can be enhanced by means of mediated learning using robots. Here we present the results of the first wave of participants involved by one of the Italian partners of the project [14].

\section{Design}

This study followed a single centre, single subject experimental design. Single-case designs are a useful starting point for establishing efficacy because they yield evidence that the technique has a clear, replicable effect on a specific behaviour. These designs also involve repeated observations, which provide close monitoring of the effects and opportunities to refine the technique. Here we used an $\mathrm{AB} A B$ design. In the $\mathrm{AB} A B$ design, alternating treatment conditions (intervention and control) are compared for one individual whose behaviour is continuously monitored. For this study, the control condition (A) was the educator's usual intervention methods. The intervention (B) was the use of the robot to achieve the same learning objective(s). Ethical approval for the conduction of the study was given by the Local Health Trust. In reporting the methodology and results of the current study, we followed the Single-Case Reporting guideline In BEhavioural interventions (SCRIBE) which was recently published to improve the reporting of single-case research [15].

\section{Setting and Materials}

The study was conducted within a public health service. The robot used was a NAO NextGen (Model H25, Version 4) humanoid robot, produced by Aldebaran Robotics. NAO is manufactured with a wide range of behaviours, including walking, standing up and sitting down, dancing, and recognising speech, sounds and objects as well as producing speech from text and playing sound files. These behaviours can all be programmed into the robot using Choregraphe, a user-friendly graphical interface that allows users to control the robot wirelessly from a tablet, laptop or desktop computer and create sequences of behaviours. An educator who attended a one-day course on the use of the NAO robot conducted all the interventions' sessions. Technical support was given only after the completion of the session.

\section{Participants}


Three preschool children with a diagnosis of ASD were recruited from the local ASD service. Main participants' characteristics are illustrated in table 1. To describe the sample, adaptive behaviour was also assessed using the Adaptive Behavior Scale Short form (SABS; [16]). SABS contains three scales each addressing different aspects of adaptive behaviour, namely Personal self-sufficiency; Community Self-sufficiency; and, Personal-Social Responsibility. For the scope of the present study, a total SABS score was derived by summing all item scores (range 0-105), with lower scores indicating less adaptive capabilities. For each child, the multidisciplinary team responsible for designing the child's care plan identified specific learning objectives to be achieved during the study.

Table 1. Participants characteristics

\begin{tabular}{|c|c|c|c|c|c|}
\hline Name & Age & Gender & Diagnosis $^{1}$ & SABS $^{2}$ & Learning objectives \\
\hline Jack & $4 \mathrm{ys} ; 9 \mathrm{~ms}$ & $\mathrm{M}$ & ASD & 27 & $\begin{array}{l}\text { - Spontaneous request } \\
\text { - Gross-motor and vocal imitation }\end{array}$ \\
\hline Andy & $4 \mathrm{ys} ; 5 \mathrm{~ms}$ & $\mathrm{M}$ & ASD & 41 & $\begin{array}{l}\text { - Spontaneous request, react to name } \\
\text { - Receptive vocabulary }\end{array}$ \\
\hline Jean & $4 \mathrm{ys} ; 5 \mathrm{~ms}$ & $\mathrm{M}$ & ASD & 42 & $\begin{array}{l}\text { - Spontaneous request, react to name } \\
\text { - Receptive vocabulary } \\
\text { - Object naming }\end{array}$ \\
\hline
\end{tabular}

\section{Control condition (A conditions)}

Each control intervention consisted of three to five 10-min consecutive one-to-one sessions, implemented once a week, during which the child was proposed with a set of playing activities using a wide variety of everyday objects (e.g., bottles, picture cards, music box) and ordinary toys (e.g., puppets; balls). Each play activity was aimed at evoking specific target behaviours, including imitation (vocal and gross-motor); communication (e.g., spontaneous request; say hello; reacting to name); and, language comprehension and speech production (i.e., object selection and naming). Each activity consisted of a training session and a target session. For example, to elicit a spontaneous request, in the training session the educator said the word "music" and immediately after a music box started to play. The educator repeated this several times. In the target session, while the music was playing, the educator randomly interrupted the music before its end. The music could start again only if the child said the word "music", in which case the educator provided a positive feedback. Otherwise, if the child did not say the target word, the educator prompted the correct word and started the activity from the beginning. The target goal for this activity was thus increasing the frequency of spontaneous requests to activate the music.

\section{Robot condition (B conditions)}

Each robot intervention consisted of three to five 10-min sessions, implemented once a week. Sessions followed the same structure as the control intervention activities, and pursued the same objectives in terms of target behaviours for achieving the identified learning objectives. For example, for the spontaneous request, NAO was programmed i.e. to dance or produce music, upon a specific request ("music"). To guarantee an immediate reaction from NAO, the educator used a tablet to initiate the chosen activity once the child had produced the target word. In this way, it was possible to avoid any lag in the robot response, thus increasing the effectiveness of the reinforcement. Further, remote control via tablet was also useful to differentiate reinforcement, so the same target word would produce different NAO behaviours according to the child's interests. More details of the activities used in this study are available at the Project's website. 


\section{Data Collection and Response Categories}

All sessions were videotaped and videos analysed. Data were collected using partialinterval recording [18]. Only target sessions were analysed. The target session was divided into successive 15 -sec sample intervals. The instant of time at the end of each sample interval was identified by a beeper. On the instant of each sample point, the observer recorded whether (1) or not (0) the target behaviour had occurred during the preceding sample interval. The score of each behaviour for each participant was expressed as the proportion of all sample intervals during which that behaviour occurred.

Behaviours observed included state of engagement, which was defined according to Kishida and colleagues [19], and goal achievement. For the scope of the current study, we assumed a positive relationship between engagement and goal achievement, for which, the more a child is engaged in an activity, the more likely she is to achieve the activity goals [25].

Table 2 provides definitions and examples for each response category related to engagement. The scheme contained 4 codes for engagement state, namely engagement (active; passive), and non-engagement (active; passive). Engagement states were not mutually exclusive. For the scope of the present contribution, we will report only on results concerning active engagement. It was calculated as the ratio between the total number of samples in which active engagement was recorded and the total number of sample intervals for each session. Goal achievement refers to the frequency with which a desired (target) behaviour occurred during each session without any prompt. It was calculated as the ratio between the total number of correct answers provided without prompts and the total number of sample intervals considered for each session.

Table 2. Definitions of codes used for the video analyses (adapted from [19]).

\begin{tabular}{|l|l|l|}
\hline Engagement & \multicolumn{1}{|c|}{ Definition } & \multicolumn{1}{|c|}{ Example } \\
\hline engagement & $\begin{array}{l}\text { A child actively participates in the activity } \\
\text { by interacting with the learning environment } \\
\text { appropriately by manipulating or gazing at } \\
\text { the materials. The child does not } \\
\text { demonstrate repetitive and/or inappropriate } \\
\text { behaviours. }\end{array}$ & $\begin{array}{l}\text { (a) A child holds and moves the brush } \\
\text { to paint, with his/her eyes on the brush } \\
\text { and paper; (b) a child looks at the robot } \\
\text { and smiles when it pronounces his/her } \\
\text { name. }\end{array}$ \\
\hline $\begin{array}{l}\text { Passive } \\
\text { engagement }\end{array}$ & $\begin{array}{l}\text { A child interacts with the environment or the } \\
\text { learning activity but in a repetitive or } \\
\text { stereotyped manner (see undifferentiated } \\
\text { engagement in [19]) }\end{array}$ & $\begin{array}{l}\text { (a) A child applauds in reaction to an } \\
\text { event without looking at the object } \\
\text { which caused it, thus demonstrating } \\
\text { that clapping is a stereotyped } \\
\text { behaviour; (b) A child preservers in } \\
\text { behaving appropriately for a previous } \\
\text { activity but not in the current one (i.e. } \\
\text { asking to play music when the activity } \\
\text { is to name a color); (c) even if a child } \\
\text { provides a correct answer, he/she does } \\
\text { not pay overt attention to the ongoing } \\
\text { activity }\end{array}$ \\
\hline $\begin{array}{l}\text { Active non- } \\
\text { engagement }\end{array}$ & $\begin{array}{l}\text { A child interacts with the environment in an } \\
\text { inappropriate manner by } \\
\text { manipulation/movement and/or vocalization. }\end{array}$ & $\begin{array}{l}\text { A child wanders around or interacts } \\
\text { with objects in a manner that it is not } \\
\text { pertinent with the ongoing activity. }\end{array}$ \\
\hline engagement & $\begin{array}{l}\text { A child does not interact with the } \\
\text { environment and does not do what is } \\
\text { expected from her/him during the activity. }\end{array}$ & $\begin{array}{l}\text { A child does not interact with any } \\
\text { material. }\end{array}$ \\
\hline
\end{tabular}

\section{Dependent Measures}

For each child with ASD, the percentage of occurrence of each separate behaviour category (active engagement; goal achievement) was calculated by dividing the number of $1 \mathrm{~s}$ for that behaviour category by the total number of sample intervals, multiplied by $100 \%$. It was hypothesized that the percentages of occurrence for active engagement 
and goal achievement categories would increase during robot conditions compared to control condition.

\section{Data analysis}

Data analysis consisted of a visual analysis aided by quasi-statistical techniques [21]. First, data analysis involved the calculation of mean percentages of the behaviour categories across conditions and visual inspection of the data. Second, to determine the effect size of the intervention, Tau-U was calculated. Tau-U can be used in single case research and examines the percentage of non-overlap of the data between conditions. Additionally, Tau-U controls for a positive control trend [22]. Tau-U, the standard deviations of Tau- $\mathrm{U}$ and the $p$ values were calculated across conditions for each pair $\left(A_{1}-B_{1} ; A_{2}-B_{2}\right)$. Then, a single aggregated omnibus effect size was calculated (Tau-U). To calculate Tau-U, a web based calculator for single case research analysis was used [20]. Tau-U may range from 0 to 100 . According to [23], with a Tau-U $\leq 50$ the intervention has to be considered ineffective, $\leq 65$ questionable, 66-92 effective, and $\geq$ 93 very effective.

\section{Results}

\section{Active engagement}

On average, Jack was engaged 34,4\% (Standard Deviation $[\mathrm{SD}]=26 \%$ ) of the time in the control condition, and $36,8 \%(\mathrm{SD}=31,1 \%)$ in the robot condition. Andy was engaged $47,2 \%(\mathrm{SD}=32,7 \%)$ of the time in the control, and $70 \%(\mathrm{SD}=21,2 \%)$ in the robot condition. Jean was engaged $38,7 \%(\mathrm{SD}=20,4 \%)$ of the time in the control condition, and $72,1 \%(\mathrm{SD}=15,2 \%)$ in the robot condition. Despite the overall positive trend for the robot intervention, only Jean's engagement in the robot condition was significantly non-overlapping with the control condition indicating an effective outcome of the robot intervention compared to the control condition (Tau- $\mathrm{U}=79 \%$; $95 \%$ confidence interval $[\mathrm{CI}]=0,1-1 ; p=0,01)$.

\section{Goal achievement}

On average, Jack's frequency of goals achieved was 16,9\% (SD=20,1\%) and 14,7\% $(\mathrm{SD}=13,5 \%)$ for the control condition and the robot condition respectively. Andy achieved $13,6 \%(\mathrm{SD}=13,1 \%)$ of the goals in the control condition compared to the $35,6 \%(\mathrm{SD}=16,9 \%)$ of the robot condition. Jean achieved $27,3 \%(\mathrm{SD}=21,5 \%)$ of the goals in the control condition, and 51,4\% (SD=27,9\%) in the robot condition. Jean was again the only participant to show a significant non-overlapping series of results indicating an effective robot intervention also in terms of goal achievement (Tau-U= $78 \% ; 95 \% \mathrm{CI}=0,1-1 ; p=0,02)$. 


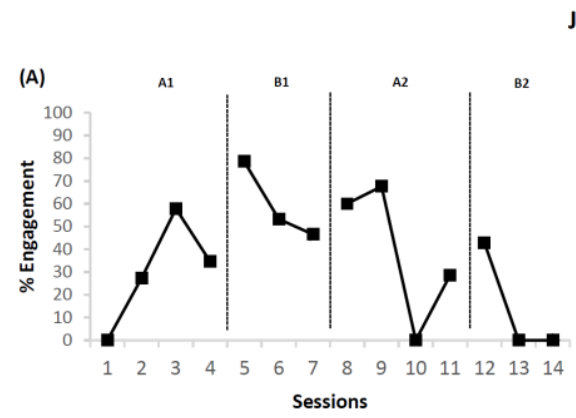

Jack
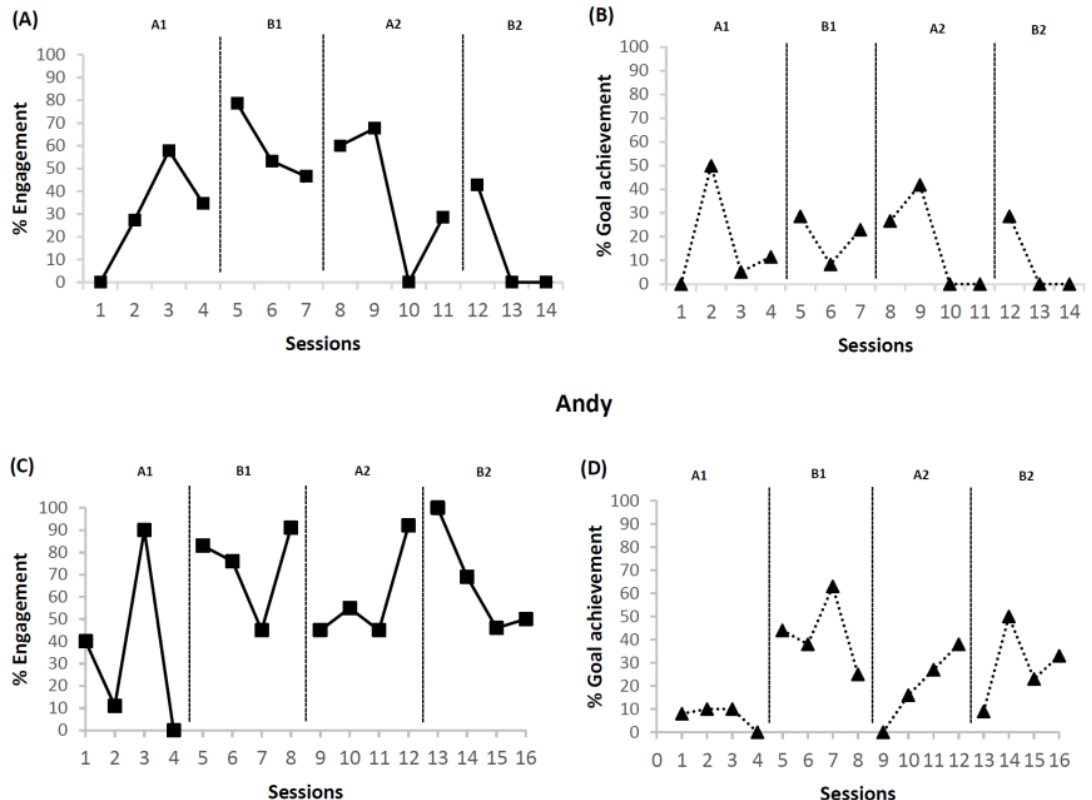

Andy

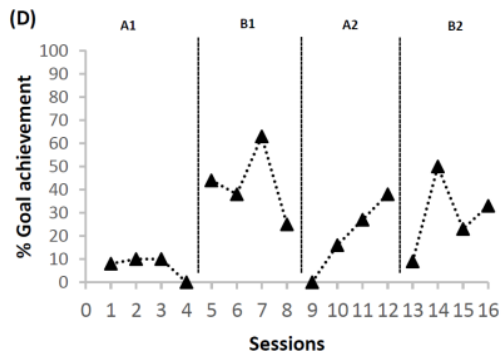

Jean
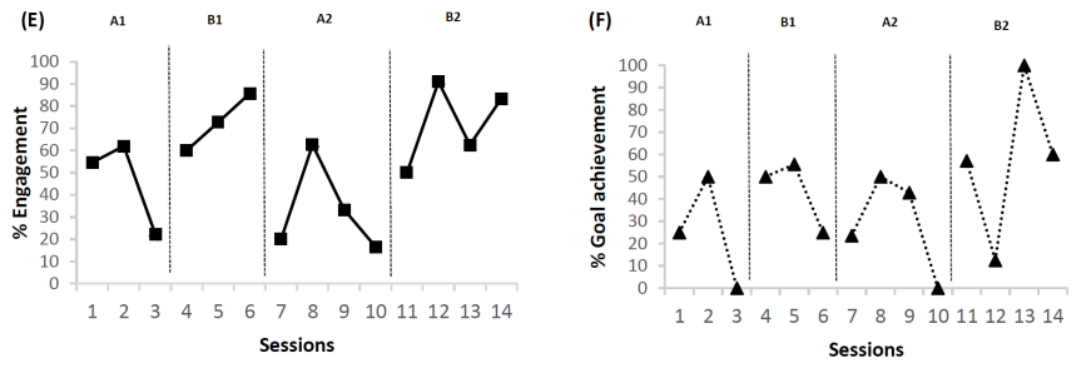

Figure 1. Frequency of engagement and goal achievement across sessions for Jack $(A ; B)$, Andy (C;D), and Jean $(E ; F)$.

\section{Discussion}

The current study was aimed at exploring whether a humanoid robot implemented in routine clinical practices could improve engagement of children with ASD during educational activities. Visual inspection of the data supported by statistical analyses show an overall positive effect of robot on engagement and goal achievement, supporting current evidence suggesting that robots may be a valid additional component to interventions targeting children with ASD [7]. In particular, Jean seemed to benefit more from the use of robot. Compared to the other participants, he was immediately attracted by the robot, and did not lose interest over the course of the sessions compared to the other participants. This may have made engagement more stable during the robot sessions, thus increasing the possibility to succeed in the learning activities [25].

Considering the small size of the sample recruited and the methodology used, however, a cautious interpretation of the present results is necessary. In this view, from the present study it can be concluded that the use of humanoid robots may be considered not detrimental to both engagement and learning achievement compared to more traditional interventions. These results may open new intervention scenarios targeting 
children with ASD, and call for further research in order to address a variety of issues related to both human-robot interaction (HRI) and ASD characteristics. For example, research has highlighted that people's interest in continuous robot usage decreases rapidly after a novelty effect vanishes [23]. Further research focusing on the use of robots in ASD interventions may address this issue by exposing children to longer interactions compared to those reported in this study. Moreover, ASD presents a unique challenge given the heterogeneity of the condition [2]. Children with ASD vary in terms of language ability, cognitive skills, behavioural difficulties, and levels of social competence. Due to this variation, individuals across the spectrum may react differently towards robots, and future research should explore the contribution of each single factor related to ASD, which may hinder the effectiveness of robots in ASD interventions.

\section{References}

[1] American Psychiatric Association. (2013). Diagnostic and statistical manual of mental disorders: DSM5. Washington, D.C: American Psychiatric Association

[2] Lord, C., \& Bishop, S. L. (2015). Recent advances in autism research as reflected in DSM-5 criteria for autism spectrum disorder. Annual Review of Clinical Psychology, 11, 53-70.

[3] Grynszpan, O., Weiss, P. L. T., Perez-Diaz, F., \& Gal, E. (2014). Innovative technology-based interventions for autism spectrum disorders: A meta-analysis. Autism, 18(4), 346-361

[4] Scassellati, B., Admoni, H., \& Mataric, M. (2012). Robots for use in autism research. Annual review of biomedical engineering, 14, 275-294.

[5] Robins, B., Dautenhahn, K., Te Boerkhorst, R., \& Billard, A. (2004, September). Robots as assistive technology-does appearance matter?. In Robot and Human Interactive Communication, 2004. ROMAN 2004. 13th IEEE International Workshop on (pp. 277-282). IEEE.

[6] Begum, M., Serna, R. W., \& Yanco, H. A. (2016). Are Robots Ready to Deliver Autism Interventions? A Comprehensive Review. International Journal of Social Robotics, 8(2), 157-181.

[7] Pennisi, P., Tonacci, A., Tartarisco, G., Billeci, L., Ruta, L., Gangemi, S., \& Pioggia, G. (2016). Autism and social robotics: A systematic review. Autism Research, 9, 165-183.

[8] Kim, E. S., Paul, R., Shic, F., \& Scassellati, B. (2012). Bridging the research gap: Making HRI useful to individuals with autism. Journal of Human-Robot Interaction, 1(1).

[9] Corsello, C. M. (2005). Early intervention in autism. Infants \& Young Children, 18(2), 74-85.

[10] Standen, P., Brown, D. J., Hedgecock, J., Roscoe, J., Trigo, M. G., \& Elgajiji, E. (2014). Adapting a humanoid robot for use with children with profound and multiple disabilities. In 10th Int. Conf. Disability, Virtual Reality and Associated Technologies (pp. 205-211).

[11] Simpson, K., Keen, D., \& Lamb, J. (2013). The use of music to engage children with autism in a receptive labelling task. Research in Autism Spectrum Disorders, 7(12), 1489-1496.

[12] Oldenziel, R., de la Bruhèze, A. A., \& De Wit, O. (2005). Europe's mediation junction: technology and consumer society in the 20th century. History and Technology, 21(1), 107-139.

[13] Royakkers, L., \& van Est, R. (2015). A literature review on new robotics: automation from love to war. International Journal of Social Robotics, 7(5), 549-570

[14] Educational Robotics for People with Learning Disabilities. Available online at http://edurob.eu/

[15] Tate, R. L., Perdices, M., Rosenkoetter, U., McDonald, S., Togher, L., Shadish, W., ... \& Sampson, M. (2016). The Single-Case Reporting Guideline In BEhavioural Interventions (SCRIBE) 2016: Explanation and elaboration. Archives of Scientific Psychology, 4(1), 10.

[16] Hatton, C., Emerson, E., Robertson, J., Gregory, N., Kessissoglou, S., Perry, J., ... \& Hillery, J. (2001) The adaptive behavior scale-residential and community (part I): towards the development of a short form. Research in developmental disabilities, 22(4), 273-288.

[17] Aldebaran Robotics. Available online at https://www.ald.softbankrobotics.com/en

[18] Wood, B. K., Hojnoski, R. L., Laracy, S. D., \& Olson, C. L. (2015). Comparison of Observational Methods and Their Relation to Ratings of Engagement in Young Children. Topics in Early Childhood Special Education, 35(4), 211-222.

[19] Kishida, Y., Kemp, C., \& Carter, M. (2008). Revision and validation of the Individual Child Engagement Record: A practitioner-friendly measure of learning opportunities for children with disabilities in early childhood settings. Journal of Intellectual and Developmental Disability, 33(2), 158170.

[20] Vannest, K.J., Parker, R.I., Gonen, O., \& Adiguzel, T. (2016). Single Case Research: web based calculators for SCR analysis. (Version 2.0) [Web-based application]. College Station, TX: Texas A\&M University. Retrieved Tuesday 17th January 2017. Available from singlecaseresearch.org 
[21] Manolov, R., Losada, J. L., Chacón-Moscoso, S., \& Sanduvete-Chaves, S. (2016). Analyzing TwoPhase Single-Case Data with Non-overlap and Mean Difference Indices: Illustration, Software Tools, and Alternatives. Frontiers in psychology, 7.

[22] Parker, R. I., Vannest, K. J., \& Davis, J. L. (2011). Effect size in single-case research: A review of nine nonoverlap techniques. Behavior Modification, 35, 303-322.

[23] Rakap, S. (2015). Effect sizes as result interpretation aids in single-subject experimental research: description and application of four nonoverlap methods. British Journal of Special Education, 42(1), 11-33.

[24] Krämer, N. C., Eimler, S., von der Pütten, A., \& Payr, S. (2011). Theory of companions: What can theoretical models contribute to applications and understanding of human-robot interaction?. Applied Artificial Intelligence, 25(6), 474-502.

[25] Iovannone, R., Dunlap, G., Huber, H., \& Kincaid, D. (2003). Effective educational practices for students with autism spectrum disorders. Focus on autism and other developmental disabilities, 18(3), $150-165$. 